\title{
Color dimensions of additive manufactured interim restorative dental material
}

\author{
Revilla-León, Marta ; Umorin, Mikhail ; Özcan, Mutlu ; Piedra-Cascón, Wenceslao
}

\begin{abstract}
STATEMENT OF PROBLEM Interim dental restorations can be fabricated by using additive manufacturing (AM) technologies. Although dental restoration contours can be easily and accurately fabricated by using computer-aided design (CAD) procedures, protocols for creating predictable color dimensions of AM interim restorations are lacking. PURPOSE The purpose of this in vitro study was to measure and compare color dimensions of different $\mathrm{AM}$ and conventional interim restorative materials. MATERIAL AND METHODS Disks $(\mathrm{N}=420)$ were fabricated by using either conventionally (CNV group) or additively manufactured (AM group) materials. The CNV group was further divided into the subgroups CNV-1 (Protemp 4; 3M ESPE) and CNV-2 (Anaxdent new outline dentin; Anaxdent). AM subgroups included AM-1 (FreePrint temp; Detax), AM-2 (E-Dent 400; Envisiontec), AM-3 (NextDent CB; NextDent), AM-4 (NextDent CB MFH; NextDent), and AM-5 (Med620 VEROGlaze; Stratasys). Color measurements in the CIELab coordinates were made by using a spectrophotometer (VITA EasyShade Advance 4.0; VITA) with a standardized photography gray card as a background under room light conditions (1003 lux). Color difference $\left(\Delta \mathrm{E}^{*}\right)$ values were calculated by using the CIE76 and CIEDE2000 formulas. The data were analyzed by using the Kruskal-Wallis test with nonparametric pairwise comparisons. RESULTS Owing to a software error, the spectrophotometer was unable to measure the color of any specimens in the AM-5 subgroup, which was consequently excluded from further analysis. Significant differences $(\mathrm{P}=.001)$ between 2 manufacturing groups were found based on the $\mathrm{L}^{*}$ variable. All subgroups were significantly different from each other for all 3 variables $(\mathrm{P}<.001)$. Pairwise comparisons revealed that all groups were significantly different from each other, except for the AM-1 and AM-2 subgroups, compared with the CNV-1 subgroup for the $\mathrm{L}^{*}$ color dimension. The $\Delta \mathrm{E}^{*}$ values calculated by using the CIE76 formula varied from 6.63 to 23.1 and by using the CIEDE2000 formula from 3.43 to 10.21, suggesting a perceptible and unacceptable color mismatch between the CNV and AM groups. CONCLUSIONS None of the additively manufactured interim materials tested matched the conventional interim materials in all 3 CIELab color dimensions.
\end{abstract}

DOI: https://doi.org/10.1016/j.prosdent.2019.06.001

Posted at the Zurich Open Repository and Archive, University of Zurich ZORA URL: https://doi.org/10.5167/uzh-197158

Journal Article

Accepted Version

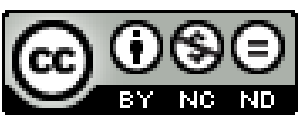

The following work is licensed under a Creative Commons: Attribution-NonCommercial-NoDerivatives 4.0 International (CC BY-NC-ND 4.0) License. 
Originally published at:

Revilla-León, Marta; Umorin, Mikhail; Özcan, Mutlu; Piedra-Cascón, Wenceslao (2020). Color dimensions of additive manufactured interim restorative dental material. Journal of Prosthetic Dentistry, 123(5):754760.

DOI: https://doi.org/10.1016/j.prosdent.2019.06.001 
Color dimensions of additive manufactured interim restorative dental material.

Marta Revilla-León DDS, MSD, ${ }^{a}$ Mikhail Umorin PhD, ${ }^{\mathrm{b}}$ Mutlu Özcan DDS, DMD, PhD, Wenceslao Piedra Cascon DDS, MS ${ }^{\mathrm{d}}$

${ }^{a}$ Assistant Professor and Assistant Program Director AEGD Program, College of Dentistry, Texas A\&M University, Dallas, Tx; Affiliate Faculty Graduate Prosthodontics, University of Washington, Seattle, WA and researcher at Revilla Research Center, Madrid, Spain.

${ }^{\mathrm{b}}$ Assistant Professor, Department of Biological Sciences, College of Dentistry, Texas A\&M University, Dallas, Texas.

'Professor and Head, Dental Materials Unit, Center for Dental and Oral Medicine, University of Zürich, Switzerland.

${ }^{\mathrm{d} A f f i l i a t e}$ Faculty Esthetic Dentistry Program, Complutense University of Madrid, Spain and Researcher at Revilla Research Center, Madrid, Spain.

\section{Keywords:}

3D printing; Additive manufacturing; Direct light processing; Interim dental restorations; Provisional dental restorations; Stereolithography.

\section{Corresponding author:}

Marta Revilla-León DDS, MSD

College of Dentistry, Texas A\&M University, Dallas, Tx. 3302 Gaston Avenue, Room 713. Dallas, Tx. 75246. Tel: +1 214886 0251. E-mail: revillaleon@tamhsc.edu 


\begin{abstract}
Statement of problem. Interim dental restorations can be fabricated using additive manufacturing (AM) technologies. Although dental restoration contours can be easily and accurately fabricated using computer aided design (CAD) procedures, protocols for creating predictable color dimensions of AM interim restorations are lacking.
\end{abstract}

Purpose. The purpose of this in vitro study was to measure and compare color dimensions of different $\mathrm{AM}$ and conventional interim restorative materials.

Material and methods. Disks $(\mathrm{N}=420)$ were fabricated using either conventionally (CNV group) or additively manufactured (AM group) materials. The CNV group was further divided into the subgroups CNV-1(Protemp 4; 3M ESPE) and CNV-2 (Anaxdent new outline dentin; Anaxdent). AM subgroups included AM-1 (FreePrint temp; Detax), AM-2 (E-Dent 400; Envisiontec), AM-3 (NextDent C\&B; NextDent), AM-4 (NextDent C\&B MFH; NextDent), and AM-5 (Med620 VEROGlaze; Stratasys). Color measurements in the CIELab coordinates were made with a spectrophotometer (Vita EasyShade Advance 4.0; Vita) using a standardized photography gray card as a background under room light conditions (1003 lux). Color difference $\left(\Delta \mathrm{E}^{*}\right)$ values were calculated using the CIE76 and CIEDE2000 formulas. The data were analyzed using the Kruskal-Wallis test with nonparametric pairwise comparisons.

Results. Due to a software error, the spectrophotometer was unable to measure the color of any specimens in the AM-5 subgroup, which was consequently excluded from further analysis. Significant differences $(P=.001)$ between 2 manufacturing groups were found based on the $\mathrm{L}^{*}$ variable. All subgroups were significantly different from each other for all 3 variables $(P<.001)$. Pairwise comparisons revealed that all groups were significantly different from each other, except for the AM-1 and AM-2 subgroups compared with the CNV-1 subgroup for the L* color 
dimension. The $\Delta \mathrm{E}^{*}$ values calculated using the CIE76 formula varied from 6.63 to 23.1 and using the CIEDE2000 formula from 3.43 to 10.21, suggesting a perceptible and unacceptable color mismatch between the $\mathrm{CNV}$ and $\mathrm{AM}$ groups.

Conclusions. None of the additively manufactured interim materials tested matched the conventional interim materials in all 3 CIELab color dimensions.

\section{CLINICAL IMPLICATIONS}

Color matching with AM interim dental materials can be difficult, as the protocol and properties of the materials used significantly differ from those of conventionally fabricated interim restorations. Custom shade guides are recommended to produce AM interim restorations with the desired shades predictably.

\section{INTRODUCTION}

Successful esthetic dental restorations depend on the ability to match the shape and the shade of the natural dentition. ${ }^{1,2}$ Computer-aided design (CAD) technologies are able to match the contralateral tooth shape using software, allowing the dental technician to design the interim restoration in a predictable manner. However, replicating the color of the natural dentition presents challenges. ${ }^{3-6}$

Additive manufacturing (AM) procedures provide an alternative manufacturing method of fabricating interim dental restorations ${ }^{7-10}$ in which a powder or liquid base material is solidified to form a 3D object. ${ }^{11-20}$ Various polymers can be selected to fabricate AM interim dental restorations. ${ }^{14}$ However, information regarding the esthetic, mechanical, and optical properties of these 3D-printed interim materials is lacking. ${ }^{21,22}$ 
Accurate perception of color discrepancies depends on the experience and training of the observers. The shade of the definitive restoration depends on accurate shade selection and communication between the dentist and technician, the dental technician's skill in handling restorative materials, and the ability of the restorative material to mimic tooth color after processing. 1,6

The CIELab system is frequently used in dentistry to quantify tooth color. ${ }^{23}$ Data obtained from computerized colorimetry or spectrophotometry allow for mathematical comparison of color properties. ${ }^{23,24}$ Dental spectrophotometers can be also used to analyze color dimensions in the CIELab coordinates. ${ }^{25-37}$ Attempts to measure the perceptibility and acceptability of color differences based on $\Delta \mathrm{E}^{*}$ using the CIE76 formula have been published. ${ }^{33-}$ ${ }^{43}$ Perceptible $\Delta E$ values of $1,{ }^{38} 2.2,{ }^{42}$ or 3.7 have been reported ${ }^{43}$ with acceptable color difference values from 2.72 to $6.8 .^{23,24,38,43,44}$ Recent publications have described a more sophisticated color difference formula that more precisely describes human perception, the CIEDE2000 formula. ${ }^{45}$ However, the thresholds of perceptible and acceptable color differences using this new formula have not yet been established.

The purpose of this in vitro study was to measure the color dimensions of different AM interim materials in the CIELab coordinates and compare them with those of conventional dental interim materials. The null hypotheses tested were that no significant difference in the $\mathrm{L}^{*}, \mathrm{a}^{*}$, and $b^{*}$ color dimensions would be found among the conventionally processed and AM groups of interim dental materials or between individual 3D-printed materials.

\section{MATERIAL AND METHODS}


Lack of information on the specimen variability precluded use of power analysis to determine the required specimen size. Furthermore, resource sharing with other projects determined that 60 specimens per material subgroup were fabricated $(n=60)$. Since the specimen group was determined by the material used in its manufacture, no specimen randomization was possible. These disks were categorized into 2 general groups, namely conventional (CNV) and additive manufactured (AM) interim material groups (Table 1). For all groups, a match to the A3.5 shade was attempted by using the corresponding materials.

For specimen fabrication of the CNV group, a ceramic sampler (Porcelain sampler; Smile line) was used to fabricate an acrylic resin disk (Pattern resin; GC) of $10 \mathrm{~mm}$ in diameter and $2.2 \mathrm{~mm}$ in thickness. This acrylic resin disk was used to make a high viscosity polyvinyl siloxane (Lab Putty; Coltène) impression to fabricate the additional conventional specimens. Two subgroups were created within the CNV group: CNV-1, which used an autopolymerizing bisacryl composite interim material (Protemp 4 temporization material, A3.5 color; 3M ESPE) and CNV-2, which used an autopolymerizing acrylic resin interim material (New outline Anaxdent, dentin A3.5 color; Anaxdent).

For the AM groups, a digital design of a disk with a 10-mm diameter and 2-mm thickness was created using open source software (Blender v2.77a; The Blender Foundation). The standard tessellation language (STL) file was used to manufacture all the AM specimens. Five AM subgroups (AM-1 to AM-5) were established based on different 3D-printing materials (Table 1).

For the AM-1, AM-3, and AM-4 groups, a DLP printer (Rapidshape D30; Rapidshape) with a $1920 \times 1080$-pixel resolution was used to fabricate the specimens following the manufacturer's instructions. The printing materials for those groups were chosen to have wavelengths compatible with the printer. 
For the AM-2 group, an SLA printer (Envisiontec VIDA printer; Envisiontec) with a XY resolution of $73 \mu \mathrm{m}$ and $\mathrm{Z}$ resolution from $25 \mu \mathrm{m}$ to $150 \mu \mathrm{m}$ was used. The interim material (EDent 400, color A3.5, Envisiontec) disks were fabricated following the manufacturer's recommendations. For AM-5, a polyjet printer (Object Eden 260VS; Stratasys) with 16- $\mu$ m resolution at the X-, Y-, and Z-axes was used to fabricate the specimens (Med620 VEROGlaze; Stratasys) following the manufacturer's instructions.

A polishing sequence of 180-, 320-, 600-, 800-, and 1400-grit SiC papers using a polishing machine (Streurs Rotopol 2; Struers) allowed standardization of the surface of all the disks and consistency of the final polish (Fig. 1). The final disk thickness of $2 \mathrm{~mm}$ was verified with digital calipers (Mitutoyo 500-196-20 6"' Digimatic digital caliper; Mitutoyo).

Color measurements in the CIELab coordinates of all the specimens were made with a spectrophotometer (VITA EasyShade Advance 4.0; Vita Zahnfabrik). The spectrophotometer was calibrated following the manufacturer's instructions before the measurements were made. A standardized photography neutral 18\% grey card (Kodak Gray Cards; Tiffen Co) was used as a background for the shade measurements. The spectrophotometer probe tip was placed perpendicular to the center of the dry disk and held until completion of the measurement. The illuminance of the room was 1003 lux and was measured using a light meter (LX1330B Light Meter; Dr. Meter Digital Illuminance).

The $\mathrm{L}^{*}, \mathrm{a}^{*}$, and $\mathrm{b}^{*}$ values for each specimen were measured 3 times and averaged before further analysis. The $\Delta \mathrm{E}^{*}$ value between material group averages was calculated using the CIE76 formula: $\Delta \mathrm{E}_{\mathrm{ab}}=\left[\left(\mathrm{L} *_{2}-\mathrm{L} *_{1}\right)^{2}+\left(\mathrm{a}{ }_{2}-\mathrm{a}{ }_{1}\right)^{2}+\left(\mathrm{b}{ }_{2}-\mathrm{b} *_{1}\right)^{2}\right]^{1 / 2}$. Same group differences were also calculated using the CIEDE2000 formula. ${ }^{45}$ 
To determine whether the variables were normally distributed, a 1-sample KolmogorovSmirnoff test was performed. The Bartlett test was used to determine whether the group and subgroup variances were homogeneous. Depending on the results of these 2 tests $(\alpha=.05)$, either a nonparametric Kruskal-Wallis test followed by nonparametric pairwise comparisons (a pairwise Dwass, Steel, Critchlow, Fligner test $)^{46}$ or a parametric ANOVA with post hoc pairwise comparisons was used to determine whether significant differences were present among the groups and which groups were different from each other. The ANOVA used nested treatment design to test for AM and CNV manufacturing and then further test for the differences among individual manufacturing materials. To test for the differences among overall AM and CNV groups using nonparametric statistics, all the AM and CNV groups were pooled into corresponding overall groups, and a Wilcoxon test was used to determine whether significant differences existed between the 2 groups for each variable. All statistical analyses were performed in R statistical environment. ${ }^{47}$

\section{RESULTS}

The spectrophotometer was unable to measure the color of all the specimens in the AM-5 group due to a spectrophotometer measurement error. Therefore, this group was excluded from the statistical analysis. The rest of the specimens were measured without any errors.

Means and standard deviations for the $\mathrm{L}^{*}, \mathrm{a}^{*}$, and $\mathrm{b}^{*}$ measurements are presented in Table 2. The boxplots of the minimum, maximum, interquartile range, medians, and the outliers for each of the $\mathrm{L}^{*}, \mathrm{a}^{*}$, and $\mathrm{b}^{*}$ variables are presented in Figure 2 . The $\Delta \mathrm{E}^{*}$ values are presented in Table 3 and 4. 
No consistent pattern was found across the 3 variables among the manufacturers. Based on the L* component, the AM-1, AM-2, AM-3 groups and CNV-1 group were consistent, and the AM-4 and, possibly, CNV-2 groups were the outliers. For component a*, AM-1 and AM-2 were similar to each other. Groups AM-3 and AM-4 were similar but had values below those for groups AM-1 and AM-2. Groups CNV-1 and CNV-2 occupied the opposite extremes of the a* value range. The pattern was different for the $b^{*}$ component, where AM-3 and AM-4 groups occupied the middle of the $b^{*}$ value range, while AM-1 and AM-2 groups occupied the opposite extremes of the $b^{*}$ value range.

After performing a Kolmogorov-Smirnoff test, the hypothesis of a normal distribution was not rejected for each group. The Bartlett test was rejected with $P<.001$ for all 3 variables, signifying that the variances of the groups were unequal and the classic analysis of variance for group comparison could not be used. This Bartlett test result also prevented the use of ANOVA with a nested treatment design to test for the differences between the AM and CNV groups in general. The Wilcoxon test of the overall difference between AM and CNV groups revealed that the AM and CNV groups were different for the $\mathrm{L}^{*}$ variable: $\mathrm{W}=17385, P=.001$, but not for the $\mathrm{a}^{*}$ or $\mathrm{b}^{*}$ variables (for $\mathrm{a}^{*}$ : $\mathrm{W}=14450, P=.958$; for $\mathrm{b}^{*}: \mathrm{W}=13998, P=.667$ ). A nonparametric Kruskal-Wallis test was then used to determine whether the individual groups were significantly different from each other for the $\mathrm{L}^{*}, \mathrm{a}^{*}$, and $\mathrm{b}^{*}$ variables. The Kruskal-Wallis test for all 3 variables was significant: $\mathrm{L}^{*}$ component: chi-squared=293.76, $\mathrm{df}=5, P<.001$; $\mathrm{a}^{*}$ component: chisquared $=338.88, \mathrm{df}=5, P<.001 ; \mathrm{b} *$ component: chi-squared $=333.75, \mathrm{df}=5, P<.001$. Given the significance of the overall test for group differences, the pairwise comparisons using nonparametric Dwass, Steel, Critchlow, Fligner tests were performed. The following groups were found to be significantly different from each other based on an experiment-wise Type I 
error of $\alpha=.05$ : $L^{*}$ component; all groups $(P<.015)$ except group AM-1 versus group CNV-1 $(P=.725)$ and group AM-2 versus group CNV-1 $(P=.474)$; component a*: all groups were pairwise significantly different (all $P<.001$ ); component $\mathrm{b}^{*}$ : all groups were pairwise significantly different (all $P<.011)$.

The $\Delta \mathrm{E}^{*}$ values calculated using the CIE76 formula varied from 6.63 to 23.1 and using the CIEDE2000 formula from 3.43 to 10.21 between the CNV and AM groups, as well as within the AM subgroups.

\section{DISCUSSION}

Both null hypotheses were rejected, as significant differences were found for the $\mathrm{L}^{*}$, $\mathrm{a}^{*}$, and $\mathrm{b}^{*}$ color dimensions between the CNV and AM groups and among the AM subgroups. It was not possible to measure the color dimensions for group AM-5 using the dental spectrophotometer, which could be explained by the color of the specimens being outside the dental color range.

A neutral grey background is frequently recommended for color matching in

dentistry. ${ }^{25,26,38,44}$ All specimens were measured following the same protocol, making the results comparable among the groups. When comparing the overall CNV and AM groups, significantly different $L^{*}$ values were found. Furthermore, the $\Delta \mathrm{E}$ values using the CIE76 formulation varied from 6.63 to 18.06 , with the lowest $\Delta \mathrm{E}^{*}$ value found between $\mathrm{CNV}-1$ and $\mathrm{AM}-3$ groups. As defined by previous studies, this $\Delta \mathrm{E}^{*}$ value can be considered an unacceptable color discrepancy. ${ }^{23,24,38-40}$ When comparing the color differences among the different AM groups, $\Delta \mathrm{E}^{*}$ values varied from 10.68 to 23.09 , which can be considered an unacceptable color discrepancy. Various authors have attempted to determine the acceptability of color discrepancy based on $\Delta \mathrm{E}^{*}$ values and have found that this value can vary from 2.72 to $6.8 .^{23,24,38-40}$ Based on 
the results of the present in vitro study, in all situations, an observer could easily detect color differences between all the interim restorative materials tested.

When the color differences were calculated with the CIEDE2000 formulation, all $\Delta \mathrm{E}^{*}$ values were consistently smaller than with the previous CEI76 formula (Fig. 3). Although there is no consistent pattern, the trend is for higher CIE76 than CIEDE2000 values. Such relatively large differences in CIEDE2000 values for corresponding small differences in CIE76 values may partly explain the wide range of perceptible and acceptable color difference thresholds reported by different authors ${ }^{23,24,38-40}$ : some small changes in calculated CIE76 color differences were perceived as rather large leading to inconsistent responses and increased variability in reported results. The CIEDE200 color difference threshold value corresponding to the CIE76 6.8 acceptable color difference threshold would be approximately 4.6. While this value is not a substitute for the experimental determination of the perceptible and acceptable color difference thresholds in dental applications, an attempt to determine the acceptable color difference threshold is reported using the CIEDE2000 formula.

Significantly different $L^{*}$ values were found among the groups tested except for the comparison of AM-1 and CNV-1 $\left(\Delta \mathrm{L}^{*}=0.06\right)$ and the comparison of AM-2 and CNV-2 $\left(\Delta \mathrm{L}^{*}=0.2\right)$ groups. Therefore, most of the processes resulted in specimens of different brightness. Greater positive values indicated higher red content in the color, and more negative values indicated higher green content. Both $\mathrm{CNV}$ groups tested presented significantly different $\mathrm{a}^{*}$ values. The CNV-1 group was more greenish $(-4.58 \pm 0.29)$ compared with the reddish CNV-2 group (4.37 \pm 0.78$)$; however, the $\mathrm{a}^{*}$ values of all the AM groups were within the range of the conventional group values. The $\mathrm{a}^{*}$ value was the color dimension with the lowest color discrepancy among the CIELab components. 
The $b^{*}$ value also varied among the groups. Higher positive values indicated a more yellow color, and higher negative values indicated a more blue color. The AM-2 group contained specimens with the lowest yellow characteristics, followed by the CNV-1, AM-3, AM-4, CNV2, and AM-1 groups.

Similar materials were expected to have similar color properties, but significant differences were found between all the CIELab components. Custom shade guides for the AM interim materials tested could facilitate accurate shade selection and improve clinician to dental laboratory communication about these novel materials. ${ }^{33-37}$

The spectrophotometer model used in this study has been used in other studies to analyze color dimensions. ${ }^{25,26,37}$ Paul et $\mathrm{al}^{25}$ compared visual color matching methods using the Vitapan classical shade guide with color matching using the Spectroshade spectrophotometer. The authors achieved better color matches with the spectrophotometer than the traditional shade guide. Their study suggests that a device can adequately substitute for human vision when color matching. The crowns made using spectrophotometer matching were preferred in $90 \%$ of situations over the crowns made by visual matching. Da Silva et al ${ }^{32}$ compared visual and instrumental shade matching methods. The authors found color matching by spectrophotometers to be more reliable than visual methods. ${ }^{48-50}$

Measuring specimen color was accomplished by holding the probe tip at 90 degrees to the specimen surface. However, minor angulations of the probe may have caused an edge-loss effect. In this effect, the illuminating beam scatters within the specimen and beyond the edge of the probe tip, especially when measuring a translucent specimen. ${ }^{50}$ The edge-loss effect could contribute to inaccurate color measurement. 
The present study had limitations, including the in vitro conditions for color measurements, the neutral grey background instead of a natural oral environment, the spectrophotometer selected, a geometric specimen instead of a natural tooth, and specimens of a different thickness than natural teeth. These factors could all amplify or reduce the color differences found. Further studies are recommended to assess the color matching capabilities of these new AM materials.

\section{CONCLUSIONS}

Based on the findings of this in vitro study, the following conclusions were drawn:

1. AM procedures resulted in significantly different $L^{*}$ color values compared with conventional restorative interim materials.

2. Significant color differences were found among the AM interim material subgroups in all 3 color dimensions. These differences resulted in clinically perceptible and unacceptable color mismatch.

3. Except for the AM-1 and AM-2 groups in the L* color dimension, the AM interim materials tested were unable to match the conventional interim materials in any CIELab color dimension.

4. Color differences calculated using the CIEDE2000 formula were consistently lower than for their corresponding CIE76 values, resulting in an approximate acceptable color difference threshold of 4.6 with the CIEDE2000 formula. 


\section{REFERENCES}

1. Sjögren G, Lantto R, Tillberg A. Clinical evaluation of all-ceramic crowns (Dicor) in general practice. J Prosthet Dent 1999;81:277-84.

2. Haselton DR, Diaz-Arnold AM, Hillis SL. Clinic assessment of high-strength all-ceramic crowns. J Prosthet Dent 2000;83:396-401.

3. Milleding P, Haag P, Neroth B, Renz I. Two years of clinical experience with Procera titanium crowns. Int J Prosthodont 1998;11:224-32.

4. Bergam B, Nilson H, Andersson M. A longitudinal clinical study of Procera ceramicveneered titanium copings. Int J Prosthodont 1999;12:135-9.

5. Belser UC, Grütter L, Vailati F, Bornstein MM, Weber HP, Buser D. Outcome evaluation of early placed maxillary anterior single-tooth implants using objective esthetic criteria: A crosssectional, retrospective study in 45 patients with a 2 to 4 -year follow-up using a pink and white esthetic scores. J Periodontol 2009;80:140-51.

6. Galluci GO, Grütter L, Nedir R, Bischof M, Belser UC. Esthetic outcomes with porcelainfused-to-ceramic and all-ceramic single-implant crowns: a randomized clinical trial. Clin Oral Impl Res 2011;22:62-9.

7. Singh V. Rapid prototyping. Materials for RP and applications of RP. IJSER 2013;4:473-80.

8. Van Noort R. The future of dental devices is digital. Dent Mater 2012:28:3-12.

9. Horn TJ, Harrysson OLA. Overview of current additive manufacturing technologies and selected applications. Sci Prog 2012:95:255-82.

10. Tapie L, Lebon N, Mawussi B, Fron-Chabouis H, Duret F, Attal JP. Understanding dental $\mathrm{CAD} / \mathrm{CAM}$ for restorations. accuracy from a mechanical engineering viewpoint. Int J Comput Dent 2015;18:343-67. 
11. Torabi K, Farjood E, Hamedani S. Rapid prototyping technologies and their applications in prosthodontics, a review of literature. J Dent Shiraz Univ Med Sci 2015;16:1-9.

12. Witkowski S. CAD/CAM in dental technology. Quintessence Dent Technol 2005;28:169-84. 13. ASTM, Committee F42 on Additive Manufacturing Technologies, West Conshohocken, Pa. 2009 Standard terminology for additive manufacturing - general principles and terminology. ISO/ASTM52900-15.

14. Revilla-León M, Özcan M. Additive manufacturing technologies used for process polymers: Current status and potential application in prosthetic dentistry. J Prosthodont 2019;28:146-58. 15. 1len S, Dutta D. On the computation of part orientation using support structures in layered manufacturing. Austin, TX, Proceedings of the Solid Freeform Fabrication Symposium; 1994. p. 259-69.

16. Puebla K, Arcaute K, Quintana R, Wicker RB. Effects of environmental conditions, aging, and build orientations on the mechanical properties of ASTM type I specimens manufactured via stereolithography. Rapid Prototyp J 2012;18:374-88.

17. Alharbi N, Osman R, Wismeijer D. Effect of build direction on the mechanical properties of 3D printed complete coverage interim dental restorations. J Prosthet Dent 2016;155:760-7.

18. Brain M, Jimbo R, Wennenberg A. Production tolerance of additive manufactured polymeric objects for clinical applications. Dent Mater 2016;32:853-61.

19. Ide Y, Nayar S, Logan H, Gallagher B, Wolfaardt J. The effect of the angle of acuteness of additive manufactured models and the direction of printing on the dimensional fidelity: clinical implications. Odontology 2017;105:108-15. 
20. Plooji JM, Maal TJ, Haers P, Borstlap WA, Kuijpers-Jagtman AM, Bergé SJ. Digital threedimensional image fusion processes for planning and evaluating orthodontics and orthognathic surgery. A systematic review. Int J Maxillofac Surg 2011;40:341-52.

21. Revilla-León M, Meyers MJ, Zandinejad A, Özcan M. A review on chemical composition, mechanical properties, and manufacturing work flow of additively manufactured current polymers for interim dental restorations. J Esthet Restor Dent 2019;31:51-7.

22. Tahayeri A, Morgan MC, Fugolin AP, Bompolaki D, Athirasala A, Pfeifer CS, et al. 3D printed versus conventionally cured provisional crown and bridge dental materials. Dent Mater 2018;34:192-200.

23. Ruyter IE, Nilner K, Möller B. Color stability of dental composite resin materials for crown and bridge veneers. Dent Mater 1987;3:246-51.

24. Douglas RD, Brewer JD. Acceptability of shade differences in metal ceramic crowns. J Prosthet Dent 1998;79:254-60.

25. Paul S, Peter A, Pietrobon N, Hämmerle CH. Visual and spectrophotometric shade analysis of human teeth. J Dent Res 2002;81:578-82.

26. Dudea D, Gasparik C, Botos A, Alb F, Irimie A, Paravina RD. Influence of background/surrounding area on accuracy of visual color matching. Clin Oral Investig 2016;20:1167-73.

27. Olms C, Setz J. The repeatability of digital shade measurement-a clinical study. Clin Oral Inv 2013;17:1161-6.

28. Tsiliagkou A, Diamantopoulou S, Papazoglou E, Kakaboura A. Evaluation of reliability and validity of three dental color-matching devices. Int J Esthet Dent 2016;11:110-24. 
29. Tsiliagkou A, Diamantopoulou S, Papazoglou E, Kakaboura A. Performance assessment of VITA Easy Shade spectrophotometer on color measurement of aesthetic dental materials. Eur J Prosthodont Restor Dent 2011;19:168-74.

30. Lee YK, Yu B, Lee SH, Cho MS, Lee CY, Lim HN. Shade compatibility of esthetic restorative materials-A review. Dent Mater 2010;26:1119-26.

31. Chu SJ, Trushkowsky RD, Paravina RD. Dental color matching instruments and systems. Review of clinical and research aspects. J Dent 2010;38s:e2-e16.

32. Da Silva JD, Park SE, Weber HP, Ishikawa-Nagai S. Clinical performance of a newly developed spectrophotometric system on tooth color reproduction. J Prosthet Dent 2008;99:3618.

33. Lee YK, Powers JM. Influence of background color on the color changes of resin composites after accelerated aging. Am J Dent 2007;20:27-30.

34. Sproull RC. Color matching in dentistry. Part II: Practical applications of the color organization. J Prosthet Dent 1973;29:556-66.

35. Farrell FC. New concept for an old problem: custom shade guide vs. conventional shade guides. Trends Tech Contemp Dent Lab 1986;3:57-8.

36. Wieder S. Custom shade guide system for composite resins. Custom J Esthet Dent 1990;2:10-2.

37. Kalantari MH, Ghoraishian SA, Mohaghegh M. Evaluation of accuracy of shade selection using two spectrophotometer systems: Vita Easyshade and Degudent Shadepilot. Eur J Dent 2017;11:196-200.

38. Judd DB, Wyszecki G. Color in business, science, and industry. 3rd ed. New York: John Wiley \& Sons; 1975. p. 102-24. 
39. Billmeyer, Saltzman. Principles of color technology, 4th ed., Wiley, Hoboken, NJ; 2019, p. 57-63.

40. Kuehni RG, Marcus RT. An experiment in visual scaling of small color differences. Color Res Appl 1979;4:83-91.

41. Seghi RR, Hewlett ER, Kim J. Visual and instrumental colorimetric assessments of small color differences on translucent dental porcelain. J Dent Res 1989;68:1760-4.

42. Johnston WM, Kao EC. Assessment of appearance match by visual observation and clinical colorimetry. J Dent Res 1989;68:812-22.

43. Ragain JC Jr, Johnston W. Minimum color differences for discriminating mismatch between composite and tooth color. J Estheth Restor Dent 2001;13:41-8.

44. Douglas RD, Steinhauer TJ, Wee AG. Intraoral determination of the tolerance of dentists for perceptibility and acceptability of shade mismatch. J Prosthet Dent 2007;97:200-8.

45. Sharma G, Wu W, Dalal E. The CIEDE2000 color-difference formula: Implementation notes, supplementary test data, and mathematical observations. Color research and application 2005;30:21-30.

46. Hollander MDA, Wolfe DA, Chicken E. Nonparametric statistical methods, $3^{\text {rd }}$ edition. Wiley; 2014. p. 202-14.

47. R Core Team. A language and environment for statistical computing. R Foundation for Statistical Computing, Vienna, Austria. 2018. https://www.R-project.org/

48. Bolt RA, ten Bosch JJ, Coops JC. Influence of window size in small-window color measurement, particularly of teeth. Physic Med Bio 1994; 39:1133-42.

49. Van der Burgt TP, ten Bosch JJ, Borsboom PC, Kortsmit WJ. A comparison of new and conventional methods for quantification of tooth color. J Prosthet Dent 1990;63:155-62. 
50. AlGhazali N, Burnside G, Smith RW, Preston AJ, Jarad FD. Performance assessment of Vita Easy Shade spectrophotometer on colour measurement of aesthetic dental materials. Eur J Prosthodont Restor Dent 2011;19:168-74. 
TABLE

Table 1. Conventionally (CNV) and additively manufactured (AM) interim materials tested

\begin{tabular}{|c|c|c|c|c|}
\hline GROUP & MANUFACTURER & $\begin{array}{l}\text { INTERIM } \\
\text { MATERIAL }\end{array}$ & $\begin{array}{l}\text { MANUFACTURING } \\
\text { PROCESS }\end{array}$ & $\begin{array}{l}\text { DEFINITION } \\
\text { PROVIDED }\end{array}$ \\
\hline CNV-1 & 3M ESPE & Protemp 4 & $\begin{array}{l}\text { Conventional } \\
\text { procedures }\end{array}$ & $\begin{array}{l}\text { Bis-acryl composite for } \\
\text { single and multiple unit } \\
\text { interim restorations. }\end{array}$ \\
\hline CNV-2 & Anaxdent & Anaxdent & $\begin{array}{l}\text { Conventional } \\
\text { procedures }\end{array}$ & PMMA acrylic resin. \\
\hline AM-1 & Detax & FreePrint Temp & $\mathrm{AM}$ & $\begin{array}{l}\text { Monomer based on acrylic } \\
\text { esters for manufacturing of } \\
\text { 3D-printed crowns and } \\
\text { bridges } \\
\text { based on acrylic esters.sent }\end{array}$ \\
\hline AM-2 & Envisiontec & E-Dent 400 & $\mathrm{AM}$ & $\begin{array}{l}\text { Monomer based on acrylic } \\
\text { esters. } \\
\text { Class IIa CE Certified } \\
\text { FDA-approved }\end{array}$ \\
\hline AM-3 & & $\mathrm{C} \& \mathrm{~B}$ & $\mathrm{AM}$ & $\begin{array}{l}\text { Class IIa CE Certified. } \\
\text { FDA-approved }\end{array}$ \\
\hline AM-4 & NextDent & $\mathrm{C} \& \mathrm{~B} \mathrm{MFH}$ & $\mathrm{AM}$ & $\begin{array}{l}\text { Micro filled hybrid } \\
\text { Class IIa CE Certified } \\
\text { FDA-approved }\end{array}$ \\
\hline AM-5 & Stratasys & $\begin{array}{l}\text { VeroGlaze - } \\
\text { MED620 }\end{array}$ & $\mathrm{AM}$ & $\begin{array}{l}\text { Monomer based on acrylic } \\
\text { esters. }\end{array}$ \\
\hline
\end{tabular}


Table 2. Means \pm standard deviations of $\mathrm{L}^{*}, \mathrm{a}^{*}$, and $\mathrm{b}^{*}$ components by manufacturer (group)

\begin{tabular}{|l|l|l|l|l|l|l|}
\hline Group & AM-1 & AM-2 & AM-3 & AM-4 & CNV-1 & CMV-2 \\
\hline L* & $81.82 \pm 0.40$ & $81.56 \pm 0.60$ & $83.14 \pm 0.46$ & $72.49 \pm 0.43$ & $81.76 \pm 0.64$ & $79.45 \pm 1.28$ \\
\hline $\mathrm{a}^{*}$ & $1.14 \pm 0.467$ & $2.42 \pm 0.72$ & $-1.31 \pm 0.28$ & $-1.59 \pm 0.26$ & $-4.58 \pm 0.29$ & $4.37 \pm 0.78$ \\
\hline $\mathrm{b}^{*}$ & $16.46 \pm 0.54$ & $39.52 \pm 0.54$ & $27.99 \pm 1.16$ & $27.28 \pm 0.32$ & $33.59 \pm 1.47$ & $24.93 \pm 1.63$ \\
\hline
\end{tabular}

AM, additively manufactured; CNV conventionally manufactured. 
Table 3. Color component $\left(\mathrm{L}^{*}, \mathrm{a}^{*}, \mathrm{~b}^{*}\right)$ differences and color difference $\left(\Delta \mathrm{E}^{*}\right)$ values between different CNV and AM groups

\begin{tabular}{|l|l|l|l|l|l|}
\hline $\begin{array}{l}\text { Comparison } \\
\text { groups }\end{array}$ & $\begin{array}{l}\text { Mean } \\
\boldsymbol{\Delta} \mathbf{L}^{*}\end{array}$ & Mean $\Delta \mathbf{a}^{*}$ & Mean $\Delta \mathbf{b}^{*}$ & $\begin{array}{l}\text { Mean } \Delta \mathbf{E}^{*} \\
\text { CIE76 }\end{array}$ & $\begin{array}{l}\text { Mean } \mathbf{\Delta E} * \\
\text { CIEDE2000 }\end{array}$ \\
\hline $\mathrm{CNV}-1$ and AM-1 & 0.06 & $5.72 \dagger$ & $17.13 \dagger$ & $\mathbf{1 8 . 0 6}$ & 9.32 \\
\hline $\mathrm{CNV}-1$ and AM-2 & 0.2 & $7 \dagger$ & $5.93 \dagger$ & $\mathbf{9 . 1 7}$ & 5.83 \\
\hline $\mathrm{CNV}-1$ and AM-3 & $1.38 \dagger$ & $3.27 \dagger$ & $5.6 \dagger$ & 6.63 & 5.43 \\
\hline $\mathrm{CNV}-1$ and AM-4 & $9.27 \dagger$ & $2.99 \dagger$ & $6.31 \dagger$ & $\mathbf{1 1 . 6 1}$ & 7.42 \\
\hline $\mathrm{CNV}-2$ and AM-1 & $2.37 \dagger$ & $5.51 \dagger$ & $8.47 \dagger$ & $\mathbf{9 . 3 6}$ & 5.41 \\
\hline $\mathrm{CNV}-2$ and AM-2 & $2.11 \dagger$ & $1.95 \dagger$ & $14.59 \dagger$ & $\mathbf{1 4 . 8 6}$ & 6.62 \\
\hline $\mathrm{CNV}-2$ and AM-3 & $3.69 \dagger$ & $5.68 \dagger$ & $1.94 \dagger$ & $\mathbf{7 . 4 3}$ & 5.94 \\
\hline $\mathrm{CNV}-2$ and AM-4 & $6.96 \dagger$ & $5.96 \dagger$ & $2.35 \dagger$ & $\mathbf{9 . 4 6}$ & 7.50 \\
\hline
\end{tabular}

Color differences considered unacceptable in bold $\left(\Delta \mathrm{E}^{*}>6.8\right)$

$\uparrow$ significant $(P<.05)$ difference 
Table 4. Color component $\left(\mathrm{L}^{*}, \mathrm{a}^{*}, \mathrm{~b}^{*}\right)$ differences and color difference $\left(\Delta \mathrm{E}^{*}\right)$ values between the AM groups. All pairwise differences significant (experiment-wise $P<.05$ )

\begin{tabular}{|l|l|l|l|l|l|}
\hline $\begin{array}{l}\text { Comparison } \\
\text { groups }\end{array}$ & $\begin{array}{l}\text { Mean } \\
\boldsymbol{\Delta} \mathbf{L}^{*}\end{array}$ & Mean $\Delta \mathbf{a}^{*}$ & Mean $\Delta \mathbf{b}^{*}$ & $\begin{array}{l}\text { Mean } \boldsymbol{\Delta} \mathbf{E}^{*} \\
\text { CIE76 }\end{array}$ & $\begin{array}{l}\text { Mean } \Delta \mathbf{E}^{*} \\
\text { CIEDE2000 }\end{array}$ \\
\hline AM-1 and AM-2 & 0.26 & 1.28 & 23.06 & $\mathbf{2 3 . 0 9}$ & 10.21 \\
\hline AM-1 and AM-3 & 1.32 & 2.45 & 11.53 & $\mathbf{1 1 . 8 6}$ & 6.35 \\
\hline AM-1 and AM-4 & 9.33 & 2.73 & 10.82 & $\mathbf{1 4 . 5 4}$ & 9.04 \\
\hline AM-2 and AM-3 & 1.58 & 3.73 & 11.53 & $\mathbf{1 2 . 2 2}$ & 5.49 \\
\hline AM-2 and AM-4 & 9.07 & 4.01 & 5.31 & $\mathbf{1 5 . 7 5}$ & 8.69 \\
\hline AM-3 and AM-4 & 10.65 & 0.28 & 0.71 & $\mathbf{1 0 . 6 8}$ & 7.55 \\
\hline
\end{tabular}

Color differences considered unacceptable $\left(\Delta \mathrm{E}^{*}>6.8\right)$ in bold 


\section{FIGURES}

Figure 1. Specimen disks fabricated using conventional and additively manufacturing procedures after polishing sequence completed.

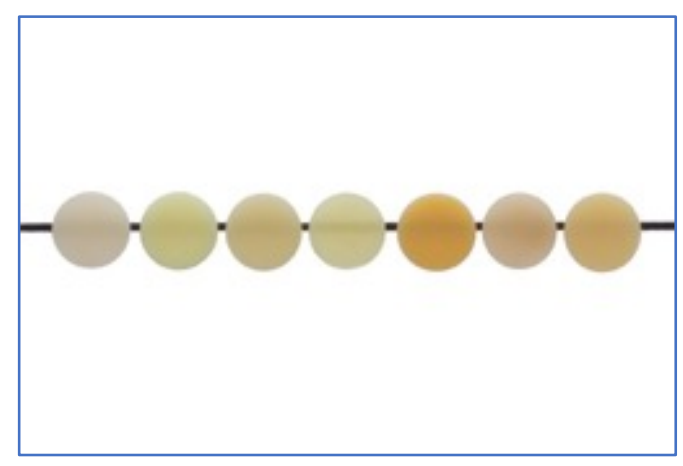

Figure 2. Minimum, maximum, interquartile range, medians, and outliers of measurements for AM-1 (FreePrint temp; Detax), AM-2 (E-Dent 400; Envisiontec), AM-3 (NextDent C\&B; NextDent), AM-4 (NextDent C\&B MFH; NextDent), and AM-5 (Med620 VEROGlaze; Stratasys), CNV-1 (Protemp 4, 3M ESPE), and CNV-2 (Anaxdent new outline dentin, Anaxdent) groups. A, L* component. $\mathrm{B}, \mathrm{a}^{*}$ component. $\mathrm{C}, \mathrm{b}$ * component.

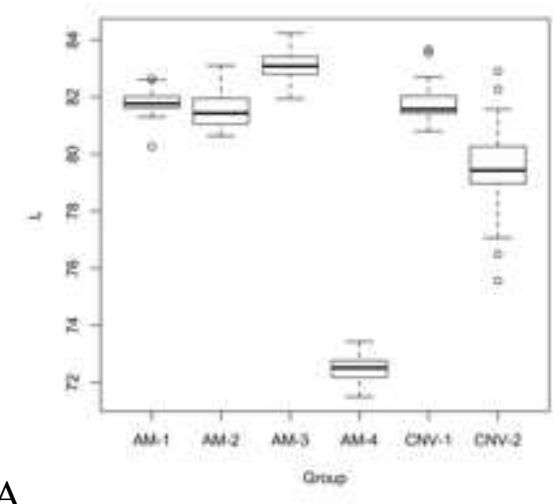

A

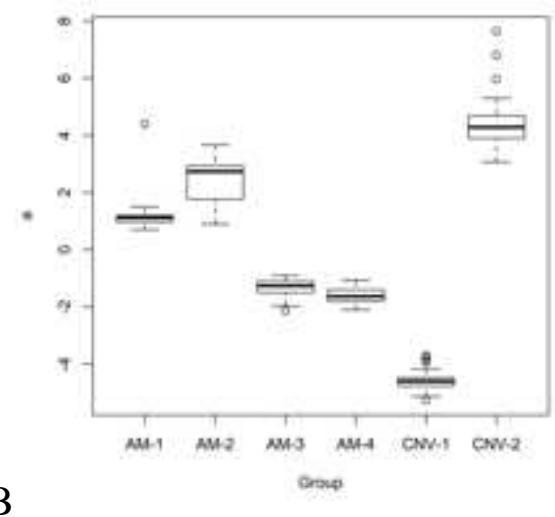

B 


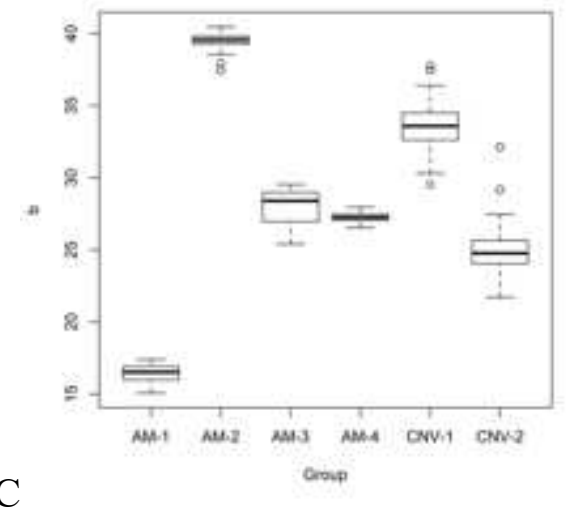

Figure 3. Scatterplot of CIEDE2000 color differences and CIE76 color differences for same pairwise group comparisons. Trend (solid line) fitted by eye using spline smoothing function smooth.spline in $\mathrm{R}$ with 0.8 smoothing parameter (spar). 6.8 threshold value (dashed vertical line) for CIE76 axis used to determine corresponding threshold (4.6, dashed horizontal line) on CIEDE2000 axis from fitted line.

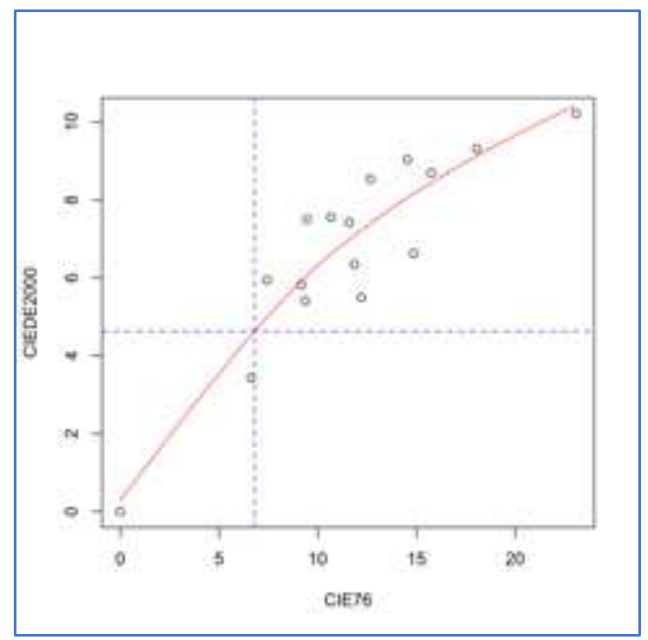

